\title{
A minimalistic model for carbon cycling in wetlands
}

\author{
$\underline{\text { J.Z. Coletti }}^{\text {a }}$, C. Hinz ${ }^{\text {a }}$, R. Vogwill ${ }^{\text {a,b }}$ and M.R. Hipsey ${ }^{\text {a,c }}$ \\ ${ }^{a}$ School of Earth and Environment, The University of Western Australia, 35 Stirling Hwy, Crawley, Western \\ Australia, 6009 \\ ${ }^{b}$ Department of Environment and Conservation, 17 Dick Perry Avenue, Kensington, Western Australia, 6983 \\ ${ }^{c}$ Centre for Ecohydrology, School of Environment Systems Engineering, The University of Western Australia, \\ 35 Stirling Hwy, Crawley, Western Australia, 6009
}

\section{Email: coletj01@student.uwa.edu.au}

\begin{abstract}
Governed by a series of biotic and abiotic processes, the size of carbon storage in wetlands is important on a global scale. However, the various feedback mechanisms and the effect that climatic fluctuations have on them are not well documented. In this study, we introduce a mechanistic model connecting hydrology, vegetation and carbon to investigate how climate variability affects wetland ecosystems and the resulting carbon budget. Our particular interest is devoted to the semi-arid wetlands found in south-west Western Australia, as they are expected to be highly sensitive to projected climatic changes due to their highly seasonal rainfall and often water limited nature. In the first part of the study, we couple a model for carbon cycling to an ecohydrological model able to resolve the dynamic partitioning of wetland hydrological environments. We then present preliminary simulations that investigate wetland carbon dynamics given different hydro-climatological conditions ranging from dry to wet within the regional range. Under the driest scenario, vegetation biomass was $182 \%$ greater than in the wettest scenario due to a shift from predominately hydrophytic to predominantly mesophytic vegetation. However, the total carbon fixation increased just $4 \%$, as the ratio of leaf area index to biomass is lower for terrestrial (woody) species than for the aquatic plants that were more abundant in wet conditions. Additionally, the total wetland respiration increased by approximately $60 \%$ due to a greater fraction of the soil becoming unsaturated, thereby promoting aerobic oxidation of organic matter stored in the soil profile. As a result, the net wetland metabolism was found to be enhanced under drier climates and the system was able to store $17 \%$ less carbon under the lowest rainfall condition when compared to the highest rainfall scenario. These preliminary results indicate that the coevolution of functional vegetation types with a dynamic hydrological environment can mediate the response of vegetation biomass and wetland carbon stores to climate shifts. Long term vegetation responses may be counter-intuitive and potentially not a good indicator for overall changes in wetland metabolism due to the dominance of the soil carbon store in wetland carbon budgets. The model presented here provides a first step to explain how changing patterns of rainfall, temperature and evapo-transpiration can significantly change the carbon retention characteristics and efficiency of wetlands, and suggests that terrestrialization of wetlands in semi-arid regions may result in a net loss of stored carbon despite potential increases in woody vegetation.
\end{abstract}

Keywords: Minimalistic modelling, carbon cycling, ecohydrology, wetland metabolism, semi-arid, climate change. 


\section{INTRODUCTION}

About a quarter of the global soil organic carbon inventory is found in wetlands, representing an important reservoir in the global carbon (C) budget (Dean and Gorham, 1998; Bridgham et al., 2006). C accumulation in wetlands is related to their typically high vegetation productivity and low organic carbon decomposition rate caused by permanent or temporary anaerobiosis associated with the waterlogged conditions that characterise many wetland environments (NRC, 1995; Dean and Gorham, 1998).

Wetland metabolism is defined as the difference between C uptake and release (Tuttle et al., 2008). Changes in climate can alter wetland metabolism, as primary production and decomposition rates are dependent on environment partitioning (Mitsch and Gosselink, 2000). Environment partitioning is defined as the division of the wetland into discrete functional zones, each characterized by different hydrological and biogeochemical processes, and therefore a different rate of $\mathrm{C}$ uptake and release. This division is primarily determined by the hydroperiod (NRC, 1995), which in turn, is a function of climate, landscape characteristics, vegetation type and water uptake strategy.

Whilst there has been an increase in the number of studies related to wetland metabolism (e.g. Bridgham et al., 2006; Rodriguez-Murillo et al., 2011), system-scale quantification of the mechanisms that control C cycling in wetlands has not been well documented (Rodriguez-Murillo et al., 2011). It remains unclear how changes in land-use and climate can impact wetland C cycling (Davidson and Janssens, 2006). Therefore, further work is required to understand the processes that control wetland metabolism.

In a previous study, an ecohydrological model that resolves the dynamic partitioning of a wetland into different hydrological functional zones was developed to better understand vegetation dynamics of semi-arid wetlands (Coletti et al., submitted). Here we extend this previous study by analysing the impact of climate on carbon cycling and wetland metabolism. In particular, we explore the hypothesis that hydrology and metabolism are non-linearly related through feedback mechanisms between abiotic and biotic variables.

Water limitation and a highly variable pattern of water delivery cause wetlands from semi-arid regions to be particularly sensitive to climatic changes. In these wetlands, rainfall occurs mostly in winter, creating a season of strong hydrologic pulses (high rainfall-low evaporation) and a season of water shortage (low rainfall-high evaporation) potentially impacting $\mathrm{C}$ storage in soil and vegetation biomass. During a period of higher water availability, fringing vegetation can provide an important input of organic matter into the soil pool as it is potentially susceptible to mortality following prolonged inundation. During the dry summers, high evaporation rate leads to a prolonged water shortage in the soil, potentially decreasing vegetation biomass. In addition, increased access to oxygen in the soil following water table depletion and the high summer temperatures can lead to high levels of organic matter degradation.

In this study, we devote our attention to the south-west Western Australia (SWWA), where the already highly seasonal rainfall (Petrone, 2010) is expected to intensify with predicted climatic changes (CSIRO, 2009). Therefore, there is a need to investigate the interactions between hydrology, ecosystem functioning and $\mathrm{C}$ metabolism. In addition, a better understanding of these interactions can help us to predict the impact of changes to land use and climate on these high value biological assets (Ramsar, 2011).

In this analysis, we use daily climate data, synthetically generated so that it can be repeated annually allowing the model to reach dynamic equilibrium. The data represents the range of dryness index (DI) values (evaporation to precipitation ratio) found in SWWA and drives a minimalistic ecohydrological model that is coupled to a $\mathrm{C}$ cycling model, which allows us to simulate the dynamic partitioning of the distinct environments found in the hypothetical wetland and the consequent wetland metabolism at a daily resolution, increasing our understanding of the mechanisms that connect hydrology and $\mathrm{C}$ cycling and the impact of climate variability on wetland metabolism.

\section{MODEL DESCRIPTION}

Our approach couples a model of C cycling (Porporato et al., 2003) with a wetland ecohydrological model (Coletti et al., submitted). The resulting model predicts dynamical surface water level, water table level and soil moisture. The processes of litterfall, $\mathrm{C}$ uptake and respiration by plants and microbes are also modelled across all functional zones of a wetland. The partitioning into functional zones of distinct hydrological function (standing water, saturated and unsaturated soil areas) is based on the water balance and constrained by the wetland geometry. Vegetation and microbial dynamics are affected by the functional zone in which they are situated, and also by climate via solar radiation, relative humidity and air temperature. As a feedback, vegetation affects hydrology via transpiration. As a result, the coupled ecohydrological model 
allows us to test the effect that landscape and climate have upon the functional zone partitioning and wetland metabolism.

The model requires input data comprised of wetland geometry (bathymetry, soil depth), precipitation, wind speed, air temperature, cloud cover and relative humidity. Initial conditions are provided for lake and water table level ( $h_{L}$ and $h_{S,}$, respectively), leaf area index ( $\left.L A I\right)$ and soil moisture $(\theta)$, carbon and bacterial biomass. The model consists of a set of ordinary differential equations briefly summarised below, which are solved at a daily time step using a $1^{\text {st }}$ order explicit finite difference method.

\subsection{Water Budget}

The major hydrological fluxes are represented in the model through linking three conceptual water storages: the open water/lake $(L)$ and the water contained in the unsaturated $(U)$ and saturated $(S)$ zones of the soil. Water fluxes in the model are defined as length of water per time $\left(\mathrm{m} \mathrm{d}^{-1}\right)$ and multiplied by relevant areas to convert to volume $\left(\mathrm{m}^{3}\right)$. The variation of lake volume with time, $d L / d t\left(\mathrm{~m}^{3} \mathrm{~d}^{-1}\right)$, is calculated as:

$$
\frac{d L}{d t}=P_{L}+Q_{c}+Q_{w}-Q_{S}-E_{L}-Q_{o u t}
$$

where $P_{L}$ is the volume of precipitation that enters the lake and $E_{L}$ is the potential evaporation integrated over the lake area. $Q_{c}$ is the inflow from the catchment area and $Q_{S}$ is the seepage that flows through the area of lake base $\left(A_{S L}\right)$ and the free saturated area $\left(A_{S}\right) . Q_{w}$ is the sum of infiltration $\left(Q_{i e}\right)$ and saturation $\left(Q_{s e}\right)$ excess mechanisms and $Q_{\text {out }}$ is the volume in excess of the lake maximum which discharges from the model. Infiltration excess is calculated as the amount of precipitation reaching the ground that is greater than the capacity of the soil to infiltrate and is a flux into the wetland standing water zone. The water balance in the unsaturated and in the saturated portion of the soil is defined respectively as follows:

$$
\begin{aligned}
& \frac{d S_{U S}}{d t}=I-E_{U}-E_{b U}-Q_{p} \\
& \frac{d S_{S A T}}{d t}=Q_{p} \pm Q_{S}-E_{S}-E_{b S}-Q_{s e}-Q_{s s}
\end{aligned}
$$

In (2), $I$ is the infiltration rate, $E_{U}$ is the transpiration from the unsaturated zone, $E_{b U}$ is the bare soil evaporation via capillarity from $A_{U}$ and $Q_{p}$ is the percolation from the vadose zone to the saturated soil zone. In (3), $E_{S}$ is the transpiration from $A_{S}, E_{b S}$ is the bare soil evaporation from $A_{S}, Q_{s e}$ is the saturation excess (the volume that surpass the soil capacity) and $Q_{s s}$ is the groundwater recharge.

\subsection{Vegetation Dynamics}

Biomass $(B)$ dynamics are governed by the rate of photosynthesis $\left(\Pi_{A}\right)$ and losses due to litterfall, $\left(L_{l}\right)$, root death $\left(R_{d}\right)$ and respiration $(R) . B\left(\mathrm{~kg} \mathrm{C} \mathrm{d}^{-1}\right)$ changes in time $(t)$, but not in space. As the spatial extent of each area with distinct hydrological function $(U, S$ and $L)$ changes, the amount of any vegetation type $i$ present at each $n$ environment changes accordingly. The balance equation for any vegetation type is:

$$
\frac{d B_{i, n}}{d t}= \begin{cases}\Pi_{A i, n} A_{n}-L_{l i, n}-R_{i, n}-R_{d i, n}+D_{i, n-1} \frac{d A_{n}}{d t} & \text { if } \frac{d A_{n}}{d t}>0 \\ \Pi_{A i, n} A_{n}-L_{l i, n}-R_{i, n}-R_{d i, n}+D_{i, n} \frac{d A_{n}}{d t} & \text { if } \frac{d A_{n}}{d t}<0\end{cases}
$$

where $\Pi_{A}\left(\mathrm{~kg} \mathrm{C} \mathrm{m}^{-2} \mathrm{~d}^{-1}\right)$ is the gross assimilation of carbon and $R\left(\mathrm{~kg} \mathrm{C} \mathrm{m}^{-2} \mathrm{~d}^{-1}\right)$ is the respiration, both defined as in Running and Coughlan (1988). $D$ is the carbon density per unit area $(=B / A)$ and $A_{n}$ is the area of the $n^{\text {th }}$ wetland zone $\left(\mathrm{m}^{2}\right)$. The rate of carbon litter production, $L_{l}$ and root death $R_{d}\left(\mathrm{~kg} \mathrm{C} \mathrm{d}^{-1}\right)$, are assumed to be approximately $0.31 \%$ (Friend et al., 1997) and $0.3 \%$ of the biomass, respectively.

Whether a specific plant type can uptake water from below or above phreatic level (or from both regions) depends on its uptake strategy. As a result, each plant type can survive in a particular hydrological environment $(U, S$ or $L)$ that matches its uptake strategy so that a different environment partitioning results in a different plant distribution and consequent wetland metabolism. The plant functional groups considered in this study are trees, grasses and aquatic types. Grasses are exclusively adapted to unsaturated soils; aquatic vegetation requires standing water and trees are adapted to both high water table level and unsaturated conditions (Coletti et al., submitted). The analysis herein is based on assumptions of particular vegetation types for each functional zone based on common SWWA vegetation types (Froend et. al., 1997). 


\subsection{Carbon decomposition}

Similarly as described by Porporato et al., (2003), the C cycle model adopted here includes twelve state variables (pools) and the associated fluxes among them (Figure 1). The particulate organic carbon (POC) is divided into three pools: litter, humus and microbial biomass, addressed by the subindexes $l, h$ and $b$, respectively. The dissolved organic carbon $(D O C)$ is also simulated and subject to leaching $\left(L_{D O C}\right)$ from the unsaturated and from the saturated environment, where the leaching losses from the $U$ zone are driven by percolation $\left(Q_{p}\right)$. Leaching losses from $S$ zone are governed by baseflow, $Q_{s s}$, and seepage, $Q_{S}$.

Each C pool is homogenously distributed within each of the three wetland environments $(n=U, S$ or $L)$, dynamically defined by the ecohydrological model presented in Section 2.1. The vegetation biomass for each environment is also represented as in Section 2.2.

Although a range of components are present in $P O C$, the litter and humus pools are assumed to be characterized by unique values of resistance to microbial decomposition $(\eta)$. These values represent the differences in decomposition rates found in proteins (faster, modelled as the litter pool) and lignin (which comprises the humus pool). Dissolved carbon is quantified in both organic $(D O C)$ and inorganic $\left(\mathrm{CO}_{2}\right)$ forms. Part of the $\mathrm{CO}_{2}$ is lost to the atmosphere, from soil respiration.

The differential equation that describes the dynamics of $P O C$ within the litter pool $\left(\mathrm{g} \mathrm{C} \mathrm{d}^{-1} \mathrm{~m}^{-3}\right)$ is:

$\frac{\boldsymbol{d P O C}_{l_{n}}}{\boldsymbol{d t}}=10^{3} L_{l_{n}} \frac{A_{n}}{V_{n}}+M_{b_{n}}-\eta_{l_{n}}+\lambda$

where $\lambda\left(\mathrm{g} \mathrm{C} \mathrm{m}^{-3}\right)$ expresses the $\mathrm{C}$ redistribution function, i.e., the reallocation of organic matter (OM) due to changes in the water table level, represented as the change in the unsaturated soil volume, $\Delta U$, relative to the total volume of soil $(M V S)$ and the concentration of $O M$ at the adjacent or at the correspondent environment:

$$
\lambda=\begin{aligned}
& \frac{\Delta U O M_{n}}{M V S}, \text { if } U^{t}>U^{t-1} \\
& \frac{\Delta U O M_{n-1}}{M V S} \text {, if } U^{t}<U^{t-1}
\end{aligned}
$$

The autochthonous litterfall in any environment, $L_{l_{n}}\left(\mathrm{~kg} \mathrm{C} \mathrm{d}^{-1} \mathrm{~m}^{-2}\right)$, equals to the sum of the litter from all plant types in that environment, multiplied by the surface area $\left(A_{n}\right)$, divided by the volume $\left(V_{n}\right)$ of the relevant environment, then multiplied by $10^{3}$ to convert to $\mathrm{g} \mathrm{C} \mathrm{d}^{-1} \mathrm{~m}^{-3}$. As a simplification, the $\mathrm{C}$ pool in the $U$ zone is constrained to be $1 \mathrm{~m}$ below the ground surface and allochthonous $\mathrm{C}$ input is ignored.

The variable $M_{b}$ indicates the bacterial mortality rate, linearly dependent on microbial biomass concentration. The influence of temperature and soil moisture on mortality is ignored. $\eta_{l_{n}}$ represents the humification rate, modelled as:

$\eta_{l_{n}}=\left(f_{\theta} k_{l} P O C_{b_{n}}\right) P O C_{l_{n}}$

where $k_{l}\left(\mathrm{~m}^{3} \mathrm{~kg} \mathrm{C}^{-1} \mathrm{~d}^{-1}\right)$ is the decomposition rate for the litter pool and $f_{\theta}$ accounts for soil moisture, $\theta(-)$, as a limiting factor for decomposition such that:

$$
f_{\theta}=\left\{\begin{array}{l}
\frac{\theta}{f_{c}}, \text { if } \theta \leq f_{c} \\
\frac{f_{c}}{\theta}, \text { if } \theta>f_{c}
\end{array}\right.
$$

In the humus pool, the $\mathrm{C}$ balance is modelled as:

$\frac{d P O C_{h_{n}}}{d t}=f_{h} \eta_{l_{n}}-n_{h_{n}}+\lambda$

where $f_{h}$ indicates the fraction of the decomposed litter that undergoes humification, varying between 0.15 and 0.35 (Porporato et al., 2003). $\eta_{h_{n}}$ is
Figure 1. Representation of the major fluxes that connect carbon pools in the system. Fluxes involving the atmosphere pool are dashed as the system is opened at that level. The three zones with distinct hydrological environment $(U, S$ and $L$ ) are depicted in brackets. 
calculated in the same way as $\eta_{l_{n}}$, but replacing $k_{l}$ by $k_{h}$ and $P O C_{l_{n}}$ by $P O C_{h_{n}} . k_{l}>k_{h}$ to reflect the characteristic higher resistance to decay of refractory organic matter (D'Odorico et al., 2003). Further, part of the humus pool is dissolved by a fraction $\left(f_{d}\right)$ to contribute to the $D O C$ pool, that also comprises the part (1$f_{a}$ ) of the respiration unable to reach the atmosphere. Variations in the $D O C$ pool are given by:

$$
\frac{d D O C_{n}}{d t}=f_{d} \eta_{h_{n}}+\left(1-f_{a}\right) R_{b}-L_{D O C}
$$

The carbon balance in the microbial biomass pool is given by:

$$
\frac{d P O C_{b_{n}}}{d t}=\left(1-f_{r}-f_{h}\right) \eta_{l_{n}}+\left(1-f_{r}-f_{d}\right) \eta_{h_{n}}-M_{b_{n}}
$$

where the $f$ variables represent the fraction of the total decomposed matter that contributes to respiration, to humification or which is dissolved (subindexes $r, h$ and $d$, respectively). $f_{r}$ must be less that $1-f_{h}$ and less than 1- $f_{d}$. If those conditions are observed, the microbial respiration $\left(\mathrm{g} \mathrm{C} \mathrm{d}^{-1}\right)$ adopts the following form:

$$
R_{b}=f_{r}\left(\eta_{l_{n}}+\eta_{h_{n}}\right)
$$

\section{ANALYSIS APPROACH}

The purpose of this analysis is to develop an understanding of the interactions and the feedback mechanisms among variables of the system and the subsequent trends in carbon storage. Here we apply the model using a time-series of daily precipitation synthetically generated by applying a stochastic rainfall model [Hipsey et al., 2003]. The one year long rainfall time-series created is not representative of any location in particular; however, the total rainfall depth and seasonal distribution were within the range typically found in SWWA. For alternate climate realizations, this base case was multiplied by two scaling factors to obtain three different rainfall scenarios with annual totals of 627,516 and $379 \mathrm{~mm}$, referred as R1, R2 and R3, respectively. As a result, the three rainfall realizations exhibit the same intrannual distribution, with rainfall concentrated mainly in the winter.

A one year long time-series of weather conditions (cloud cover, wind speed, temperature and relative humidity) was adopted for each precipitation scenario and was obtained from actual SWWA field data (Narrogin, WA). The three climate scenarios (rainfall and weather) were then used as input for the model by repeating the one year long climate data 50 times, to

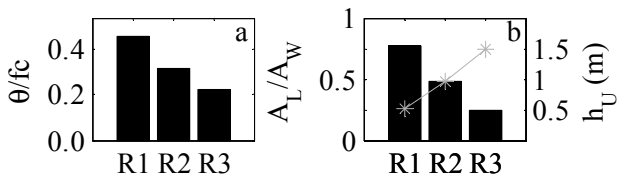

Figure 2. (a) Annual average for soil moisture $\left(\mathrm{m}^{3} \mathrm{~m}^{-3}\right)$, (b) water table depth (meters below soil surface, grey line) and lake area, $A_{L}$, relative to the total wetland area, $A_{W}\left(\mathrm{~m}^{2} \mathrm{~m}^{-2}\right)$. ensure the system reached dynamic equilibrium (quasi steady state). The key output of these scenarios was three distinct hydrological regimes that were used to elucidate the sensitivity of carbon cycling to climate.

As rainfall decreased from the wettest (R1) to the driest (R3) scenario, the annual average soil moisture decreased from $0.19 \mathrm{~m}^{3} \mathrm{~m}^{-3}$ to $0.087 \mathrm{~m}^{3} \mathrm{~m}^{-3}$ and lake area from 74 to $32 \%$ of the total wetland domain (Figure 2). Water table depth $\left(h_{U}\right)$ moved from 50 to $150 \mathrm{~cm}$ below the surface.

When available, vegetation parameters were obtained from studies carried on SWWA's wetlands (Finlayson, 2005; Froend and McComb, 1994). Otherwise, parameters from other semi-arid regions were used (e.g. Jarosz et al., 2008; Kanniah et al., 2010). Parameters for the $\mathrm{C}$ decomposition model are presented in Table 1.

Table 1. List of non dimensional parameters for the C cycling model, based on D'Odorico et al. (2003).

$\begin{array}{ll}\text { Rate of mortality of biomass bacterial } & k_{c b U}{ }^{*}=2.8 \times 10^{-3} ; k_{c b S}=1.5 \times 10^{-3} ; k_{c b L}=3.2 \times 10^{-3} \\ \text { Rate of decomposition for } P O C_{l} & k_{l U}=0.025 \times 10^{-3} ; k_{l S}=0.009 \times 10^{-3} ; k_{l L}=0.008 \times 10^{-3} \\ \text { Rate of decomposition } P O C_{h} & k_{h U}==1.6 \times 10^{-6} ; k_{h S}=0.6 \times 10^{-6} ; k_{h L}=0.7 \times 10^{-6} \\ \text { Fraction of } P O C_{l} \text { that goes to } P O C_{h} & f_{h U}=0.25 ; f_{h S}=0.25 ; f_{h L}=0.25 \\ \text { Fraction of microbial mass that goes to respiration } & f_{r U}=0.6 ; f_{r S}=0.6 ; f_{r L}=0.6 \\ \text { Fraction of } P O C_{h} \text { that goes to microbial mass } & f_{d U}=0.0003 ; f_{d S}=0.0003 ; f_{d L}=0.0003 \\ \text { Fraction of microbial respiration that leaves the soil } & f_{a U}=0.9 ; f_{a S}=0.1 ; f_{a L}=0.1 \\ { }^{*} U, S \text { and } L \text { represent the environment of relevance. } & \end{array}$

\section{WETLAND METABOLISM SENSITIVITY TO WETLAND PARTITIONING}

In comparing the distinct rainfall scenarios, resulting water availability and the subsequent environmental partitioning changed the volume and form of $\mathrm{C}$ storage. The decreased rainfall scenario (R3) increased vegetation biomass (as aboveground $\mathrm{C}$ storage) throughout the wetland domain (Figure 3a). However, the 
total C (soil plus vegetation) was reduced, as a higher respiration ( $45 \%$ greater than in the wettest scenario) occurred when a greater portion of the soil became unsaturated due to a lower water table level (Figure $2 b$ ).

In the wettest scenario (R1), vegetation showed the lowest biomass (Figure 3a). In this case, the wetland was dominated by aquatic plants and annual grasses that occupy moist upland areas. Frequent mortality caused by floods and persistent soil saturation made it difficult for trees to persist. However, despite a relatively low litterfall production, the $\mathrm{C}$ stored under the $\mathrm{R} 1$ scenario was the highest. The relatively scarce litter created was more stably stored in the hydric wetland soils (belowground storage), as microbial respiration was inhibited by the saturated conditions. In the wettest scenario, $93 \%$ of the total carbon is stored in the soil. In terms of LAI, the R1 scenario showed an even distribution among plant types, with a slightly greater portion of carbon uptake as photosynthesis coming from aquatic plants (Figure $3 b$ ).

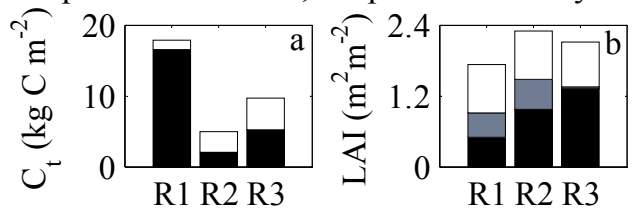

Figure 3. (a) Total $\mathrm{C}$ stored in the system (vegetation biomass in white, soil storage in black) and (b) LAI distribution $\left(\mathrm{m}^{2} \mathrm{~m}^{-2}\right)$. LAI from trees is depicted in black, from grasses in grey and from aquatic plants in white.

Under the driest scenario (R3), trees represented $62 \%$ of the vegetation LAI (Figure 3b). The total vegetation biomass was the highest (282\% greater than in the R1 scenario), as depicted in Figure 3a. Nevertheless, when compared to R1 scenario, the C uptake from atmosphere $\left(\Pi_{A}\right)$ increased just $\sim 4 \%$ because of the lower $\mathrm{C}$ uptake potential per biomass found in trees as opposed to grasses and aquatic plants. Grasses and aquatic plants were more abundant under a R1 and R2 scenarios (Figure 3b). Soil storage decreased by almost $70 \%$ (Figure 3a), caused by the enhanced microbial respiration rate that unsaturated conditions allow (Figure 4a). Since vegetation was a major component of the total respiration, this scenario generated the highest carbon efflux to the atmosphere (Figure 4a).

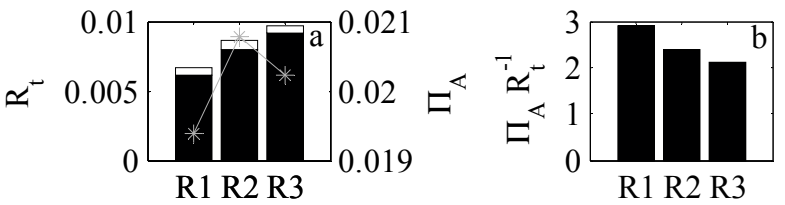

Figure 4. (a) Plants (black bars) and microbial (white bars) respiration and $\mathrm{C}$ uptake via photosynthesis by vegetation $\left(\mathrm{g} \mathrm{C}^{2}\right)$. (b) Carbon storage efficiency, represented by the total $\mathrm{C}$ uptake divided by total respiration $\left(\mathrm{g} \mathrm{C} \mathrm{m}^{2} \mathrm{~g} \mathrm{C} \mathrm{m}^{-2}\right)$

Microbial respiration, however, reached its peak under the intermediate scenario (R2) (Figure 4a), as a result of the soil moisture varying annually from 10 to $70 \%$ of field capacity (Figure 2a). Under these ideal soil moisture conditions for microbial biomass population to grow, the total $\mathrm{C}$ accumulated in the wetland was the lowest (Figure 3a). Indeed, approximately $88 \%$ less $\mathrm{C}$ is accumulated in $\mathrm{R} 2$ than in the R1 scenario, despite having the highest LAI (Figure 3b) and the highest $\mathrm{C}$ uptake, $\Pi_{A}$ (Figure $4 \mathrm{a}$ ). The R2 scenario also presented the highest diversity of vegetation groups with the most even distribution among plant functional types (Figure 3b).

Overall, increasing soil moisture and water table levels increased wetland $\mathrm{C}$ storage efficiency ( $\mathrm{C}$ uptake divided by $\mathrm{C}$ respired). Under the $\mathrm{R} 1$ scenario, the limited atmospheric carbon uptake was compensated by a reduced respiration rate, creating a low system metabolism, i.e., high storage efficiency related to belowground $\mathrm{C}$ accumulation (Figure $4 \mathrm{~b}$ ). The higher aboveground storage found in R2 and R3 scenarios was not sufficient to compensate the loss of $\mathrm{C}$ as $\mathrm{CO}_{2}$ by microbial respiration in the more aerated soils.

\section{CONCLUSIONS AND FUTURE WORK}

Decreased water availability decreased $\mathrm{C}$ storage significantly. The decrease in soil moisture and water lake area decreased the biomass of annual grasses and aquatic plants, so under the R3 scenario the environment became dominated by trees. When compared to grasses and aquatic plants, trees can store more $\mathrm{C}$ in their woody stems, but they have a lower ability to uptake $\mathrm{C}$ via photosynthesis, due to a lower LAI to biomass ratio if compared to grasses or aquatic plants. However, the most important factor to cause low $\mathrm{C}$ wetland storage under dryer R3 conditions was the depletion in the water table level, which increased soil respiration as the microbes accelerated $\mathrm{C}$ consumption under non-saturated conditions. Therefore, this is a potential relation between a drying climate and terrestrial $\mathrm{C}$ storage in wetlands, as the primary $\mathrm{C}$ pool shifts from belowground to aboveground. However, in the context of management, although vegetation biomass and biodiversity can be a proxy to evaluate the general "health" of an ecosystem, these results indicate that they did not represent the $\mathrm{C}$ storage efficiency of a wetland. 
It is important to note that the resultant $\mathrm{C}$ storage pools and net metabolism are related to the chosen parameters for respiration, photosynthesis and microbial respiration. The results may also be sensitive to the set of functional types of vegetation with their distinct water uptake strategies, and only one set has been represented in this study. Sensitivity to plant types and a different combination of vegetation parameters could lead to different patterns in the overall metabolism and $\mathrm{C}$ storage. To test these effects more deeply, a sensitivity analysis to parameters and water uptake strategy will be made in a following study.

\section{References}

Bridgham, S.D., Megonigal, J.P., Keller, J.K., Bliss, N.B. and Trettin, C. (2006). The carbon balance of North American Wetlands, Wetlands, 26, 889-916.

Coletti, J., Hinz, C., Vogwill, R. and Hipsey, M. (submitted). Behavioural Insights into Wetland Ecohydrological Dynamics: Soil, Climate and Vegetation Controls in Semi-Arid South-Western Australia.

CSIRO. (2009). Water yields and demands in south-west Western Australia, Summary of a report to the Australian Government from the CSIRO South-West Western Australia Sustainable Yields Project.

D’Odorico, P., Laio, F., Porporato, A. and Rodriguez-Iturbe, I. (2003). Hydrologic controls on soil carbon and nitrogen cycles. II. A case study, Advances in Water Resources, 26, 59-70.

Davidson, E. A. and Janssens, I. A. (2006). Temperature sensitivity of soil carbon decomposition and feedbacks to climate change, Nature, 440, 165-173.

Dean, W. and Gorham, E. (1998). Magnitude and significance of carbon burial in lakes, reservoirs, and peatlands, Geology, 26, 535-538.

Finlayson, C. M. (2005). Plant Ecology of Australia's Tropical Floodplain Wetlands: A Review. Annals of Botany, 96: 541-555.

Froend, R.H., Halse, S.A. and Storey, A.W. (1997). Planning for the recovery of Lake Toolibin, Western Australia. Wetlands Ecology and Management, 5, 73-85.

Froend, R. H. and McComb, A. J. (1994). Distribution, Productivity and Reproductive Phenology of Emergent Macrophytes in Relation to Water Regimes at Wetlands of South-western Australia. Aust. J. Mar. Freshwater Res., 45, 1491-508.

Hipsey, M. R., Sivapalan, M. and Menabde, M. (2003). A risk-based approach to the design of rural water supply catchments across Western Australia. Hydrological Sciences-Journal-Des Sciences Hydrologiques, 48(5), 709-727.

Jarosz, N., Brunet, Y., Lamaud, E., Irvine, M., Bonnefond, J. and Loustau, D. (2008). Carbon dioxide and energy flux partitioning between the understorey and the overstorey of a maritime pine forest during a year with reduced soil water availability, Agricultural and Forest Meteorology, 148, 1508-1523.

Kanniah, K.D., Beringer, J., and Hutley, L. B. (2010).The comparative role of key environmental factors in determining savanna productivity and carbon fluxes: A review, with special reference to northern Australia. Progress in Physical Geography, 34, 459-490.

Lohammar, T., Larsson, S., Linder, S. and Falk, S. (1980). FAST: Simulation Models of Gaseous Exchange in Scots Pine, Ecological Bulletins, 32, 505-523.

Mitsch, W. J. and Gosselink, J. G. (2000), Wetlands, third ed., Wiley, NewYork.

NRC. 1995. Wetlands Characteristics and Boundaries, National Research Council, National Academy Press.

Petrone, K. C., J. D. Hughes, T. G. Van Niel, and R. P. Silberstein. (2010). Stream flow decline in southwestern Australia, 1950-2008, Geophysical Research Letters, 37, L11401.

Porporato, A., D’Odorico, P., Laio, F., Rodriguez-Iturbe, I. (2003). Hydrologic controls on soil carbon and nitrogen cycles. I. Modeling scheme, Advances in Water Resources. 26, 45-58.

Ramsar. (2008). The List of Wetlands of International Importance. Accessed in April, 2009. Available on http://www.ramsar.org/sitelist.pdf

Rodriguez-Murillo, J.C., Almendros, G. and Knicker, H. (2011). Wetland soil organic matter composition in a Mediterranean semiarid wetland (Las Tablas de Daimiel, Central Spain): Insight into different carbon sequestration pathways, Organic Geochemistry, in Press, Corrected Proof.

Running, S.W. and Coughlan, J.C., (1988). A general model of forest ecosystem processes for regional applications. I. Hydrologic balance, canopy gas exchange and primary production processes, Ecological Modelling, 42, 125-154.

Running, S.W. and Gower, S. (1991). FOREST-BGC, A general model of forest ecosystem processes for regional applications. II. Dynamic carbon allocation and nitrogen budgets, Tree Physiology 9, 147-160.

Tuttle C., L., Zhang, L. and Mitsch, W. J. (2008). Aquatic metabolism as an indicator of the ecological effects of hydrologic pulsing in flow-through wetlands, Ecological Indicators, 8, 795- 806. 